\title{
Ativos intangíveis e criação de valor: análise da produção científica
}

Intangible assets and value creation: analysis of scientific production

\author{
L. Nunes-Silva ${ }^{1}$; A. Malacarne ${ }^{2}$; R. De-Bortoli ${ }^{3}$ \\ ${ }^{1}$ Gestão e Negócios, Instituto Federal do Piauí, 64.760-000, São João do Piauí-PI, Brasil \\ ${ }_{2}^{2}$ Programa de Pós-Graduação em Ciência da Propriedade Intelectual, Universidade Federal de Sergipe, 49400-000, \\ São Cristóvão-SE, Brasil \\ ${ }^{3}$ Departamento de Educação Física, Universidade Federal de Sergipe, 49400-000, São Cristóvão-SE, Brasil \\ *liaria.nunes@ifpi.edu.br \\ (Recebido em 01 de maio de 2021; aceito em 12 de novembro de 2021)
}

\begin{abstract}
Os ativos intangíveis são relevantes para a geração de valor organizacional nos diversos setores da economia. $\mathrm{O}$ objetivo desta pesquisa é analisar a produção científica sobre ativos intangíveis, destacando as suas contribuições para a criação de valor organizacional nas Instituições de Ensino Superior. Esta é uma pesquisa quantitativa e qualitativa, quanto à abordagem, e exploratória, quanto ao objetivo. Foram realizadas três buscas na base bibliográfica SCOPUS. Os resultados evidenciaram que todos os grupos de ativos intangíveis são fundamentais na criação de valor organizacional, e que as pesquisas na área vêm ganhando repercussão no ambiente científico ao longo do tempo. Percebeu-se que o setor educacional é pouco abordado nessas pesquisas, ao passo que o setor empresarial recebe maior atenção dos pesquisadores. Além disso, observou-se a existência de um núcleo de países/territórios mais produtivo, em relação à origem dessas publicações. Pesquisas demonstrando a atuação das Instituições de Ensino Superior no desenvolvimento científico e tecnológico podem contribuir para a criação de valor organizacional. A difusão do conhecimento, a criação de produtos ou oferta de serviços resultantes das suas atividades, além de fortalecer o valor da marca diante dos públicos estratégicos, apoia a tomada de decisão em relação aos investimentos em ciência, tecnologia e inovação.
\end{abstract}

Palavras-chave: Instituição de Ensino Superior, produção científica, economia do conhecimento.

Intangible assets are relevant to the generation of organizational value in the various sectors of the economy. The objective of this research is to analyze the scientific production on intangible assets, highlighting their contributions to the creation of organizational value in Higher Education Institutions. This is a quantitative and qualitative research, regarding the approach, and exploratory, regarding the objective. Three searches were performed in the SCOPUS bibliographic database. The results showed that all groups of intangible assets are fundamental in creating organizational value, and that research in the area has been gaining repercussions in the scientific environment over time. It was noticed that the educational sector is rarely addressed in these surveys, while the business sector receives greater attention from researchers. In addition, a more productive nucleus of countries / territories was observed in relation to the origin of these publications. Research demonstrating the performance of Higher Education Institutions in scientific and technological development can contribute to the creation of organizational value. The dissemination of knowledge, the creation of products or the provision of services, resulting from its activities, in addition to strengthening the brand value before strategic audiences, supports decision-making in relation to investments in science, technology and innovation.

Keywords: Higher Education Institution, scientific production, knowledge economy.

\section{INTRODUÇÃO}

A transição da economia industrial para a economia do conhecimento provocou transformações no perfil das organizações, sobretudo em relação à importância conferida aos ativos intangíveis, elementos diferenciadores e essenciais para a geração de valor organizacional. O reconhecimento e gerenciamento desses ativos é uma prática que merece ser implementada por organizações intangível-intensivas e tangível-intensivas, visto que o seu impacto reflete diretamente na rentabilidade empresarial, tanto em economias desenvolvidas, quanto em desenvolvimento [1-3]. 
A nova economia entende os ativos intangíveis como fatores críticos que interferem na criação de valor corporativo, transferindo para eles a responsabilidade pela geração de maiores ganhos econômicos e valor para os acionistas [4]. Coincidindo com os anos 2000, os investimentos em capital intangível superaram os investimentos em ativos tangíveis. A principal razão para essa mudança de foco das aplicações está associada com o fato de os ativos intangíveis ou intelectuais possuírem capacidade de aumentar o valor corporativo das organizações. Já os ativos tangíveis, configurados essencialmente como mercadorias ou commodities, estão igualmente disponíveis para todos os concorrentes, portanto são incapazes de criar valor considerável e conferir vantagem competitiva [5].

Os ativos intangíveis ou ativos de natureza intelectual, normalmente resultantes dos processos de pesquisa e desenvolvimento $(\mathrm{P} \& \mathrm{D})$, inovação e conhecimento, possibilitam às organizações retornos elevados e posições competitivas dominantes. Em alguns mercados, as vantagens geradas a partir desse capital proporcionam a conquista de monopólios temporários [6]. Contudo, para ser reconhecido como ativo intangível - não monetário identificável sem substância física é necessário que a organização comprove que o item atende aos requisitos de sua definição, bem como aos critérios de reconhecimento. Um ativo é identificável como intangível quando for separável ou resultar de direitos contratuais ou de outros direitos legais. Eles são reconhecíveis quando for provável que os benefícios econômicos futuros esperados atribuíveis ao ativo serão gerados em favor da organização e o custo do ativo deve ser mensurável com segurança [7].

Diante da diversidade de terminologias atribuídas aos ativos intangíveis [8] e buscando um entendido holístico sobre o tema, diversos pesquisadores, como Edvinsson e Malone (1998) [9], Stewart (1998) [10] e Jóia (2001) [11], propuseram taxonomias similares, muitas vezes complementares, para esses grupos de ativos. Kayo et al. (2006) [12], por exemplo, agruparam os ativos intangíveis em quatro subclasses: a) Ativos humanos; b) Ativos de inovação (pesquisa e desenvolvimento, patentes, fórmulas secretas, know-how tecnológico); c) Ativos estruturais; d) Ativos de relacionamento (marcas, logos, trademarks, direitos autorais). Já Macagnan (2007) [13], apresentou uma classificação semelhante, porém mais abrangente: a) Indicadores de capital humano; b) Capital estrutural tecnológico; c) Capital estrutural organizativo; d) Capital relacional do negócio; e) Capital relacional social.

Trazendo a discussão para o cenário da educação brasileira, o crescimento do número de Instituições de Ensino Superior (IES) privadas e a consequente ampliação do número de matrículas ocorrida a partir dos anos de 1990 [14], provocaram uma acirrada competição entre as instituições do setor educacional no Brasil, promovendo a ideia de criação de valor corporativo como estratégia competitiva de diferenciação para o mercado. No âmbito das IES públicas, ainda que apresentem características distintas das IES privadas, também demonstraram reconhecer a necessidade de criação de valor organizacional pois investem no desenvolvimento de pesquisas atreladas à inovação e na transferência de tecnologia [15-17].

As IES são polos geradores de ativos intangíveis e legítimas instituições do conhecimento. O conhecimento é representado nas entradas (inputs) e nas saídas (outputs) dos processos de ensino, pesquisa e extensão. Diante desse cenário, as políticas de geração, reconhecimento e gestão dos ativos intangíveis dessas instituições configuram-se como estratégias de diferenciação, capazes de posicionar as IES em relação aos públicos estratégicos. A inserção dos ativos intangíveis no mesmo patamar de importância dos ativos tangíveis torna-se imprescindível para a colocação da IES no cenário educacional. Assim, torna-se necessário, inclusive, a publicação de informações sobre o capital intelectual, complementando as tradicionais informações econômicas, financeiras e orçamentárias $[18,19]$.

Assim, a partir da relevância dos ativos intangíveis na criação de valor organizacional nos diversos setores da economia, bem como do entendimento de que as IES são consideradas instituições intangível-intensivas, este artigo tem o objetivo de analisar a produção científica sobre ativos intangíveis, destacando as suas contribuições para a criação de valor organizacional nas Instituições de Ensino Superior. 


\section{MATERIAL E MÉTODOS}

Esta é uma pesquisa quantitativa e qualitativa, quanto à abordagem, e exploratória, quanto ao objetivo. Para atingir o objetivo proposto, realizou-se três buscas na base de dados SCOPUS. Na primeira, direcionada para uma análise quantitativa, buscou-se obter informações acerca da produção científica sobre ativos intangíveis de maneira mais ampla, identificando a quantidade de artigos publicados por ano, os países mais produtivos e as áreas do conhecimento que mais abordam o tema. Para tanto, utilizou-se as expressões 'intangible' and 'assets' como buscador. Foram selecionados artigos que apresentaram a expressão de busca no título, resumo ou palavraschave, em um recorte temporal de 39 anos, abarcando o período entre 1979 a 2018. Para a definição do período de cobertura da pesquisa foi considerado como início o ano do segundo artigo encontrado, tendo em vista o hiato de 70 anos entre as primeira e segunda publicações.

A segunda busca foi direcionada para a coleta de artigos com ênfase na gestão dos ativos intangíveis, bem como na sua capacidade de criação de valor. Para isto, utilizou-se a expressão 'intangible' and 'assets' and 'value creation'. Pretendendo identificar publicações recentes sobre o tema, empregou-se um recorte temporal de três anos, coletando artigos no período de 2016 a 2018 que apresentaram, total ou parcialmente, os termos de busca no título, resumo ou palavraschave. Foram selecionados somente artigos em periódicos revisados por pares, desconsiderando, portanto, outros tipos de documentos, como trabalhos apresentados em conferências e capítulos de livros. Para garantir que os artigos selecionados atenderiam ao objetivo da pesquisa, analisouse criteriosamente seus resumos e conclusões. Para isso, foi elaborado um roteiro estruturado com as variáveis: Título, Autor, Objetivo da pesquisa, Palavras-chave, Conclusão e Organização pesquisada.

A terceira busca objetivou identificar a produção científica sobre ativos intangíveis enquanto elementos criadores de valor organizacional no âmbito das IES. Para tanto, definiu-se duas expressões 'intangible' and 'assets' and 'value creation' and 'higher education institutions' $\mathrm{e}$ 'intangible' and 'assets' and 'value creation' and 'university' como termos de busca e um recorte temporal de três anos, 2016 a 2018. Como resultou somente em uma publicação, o recorte foi ampliado para cinco anos, 2014 a 2018, para localizar um número maior de publicações. Foram selecionados artigos que apresentaram, total ou parcialmente, os termos de busca no título, resumo ou palavras-chave. Os artigos foram analisados de acordo com as variáveis: Título, Autor, Objetivo da pesquisa, Palavras-chave e Conclusão.

\section{RESULTADOS E DISCUSSÃO}

Com a realização da busca na base de dados SCOPUS e considerando o recorte temporal de 1979 a 2018, foram identificados 3.283 artigos. Verificou-se que o primeiro registro de publicação científica sobre ativos intangíveis na base bibliográfica ocorreu a 113 anos. Porém, o tema não se mostrou, à época, assunto de interesse, visto que houve uma lacuna de 70 anos nessa área de pesquisa, entre 1908, ano da primeira publicação, e 1978.

A retomada de publicações deu-se em 1979 e, de uma forma geral, pode ser percebido pelo crescimento do número de artigos publicados. Os dados coletados no recorte temporal de 39 anos, a partir da expressão de busca 'intangible' and 'assets,' indicam que a difusão do conhecimento acerca do tema começou a ganhar espaço na base bibliográfica pesquisada, ainda que de maneira discreta, a partir de 1979, ano em que houve duas publicações. Ainda que o volume de publicações tenha sofrido oscilações em alguns anos da série, nota-se que no início da década de 1990 o número de publicações apresentou uma tendência alta de crescimento, acentuando-se a partir dos anos 2000 (Figura 1). 


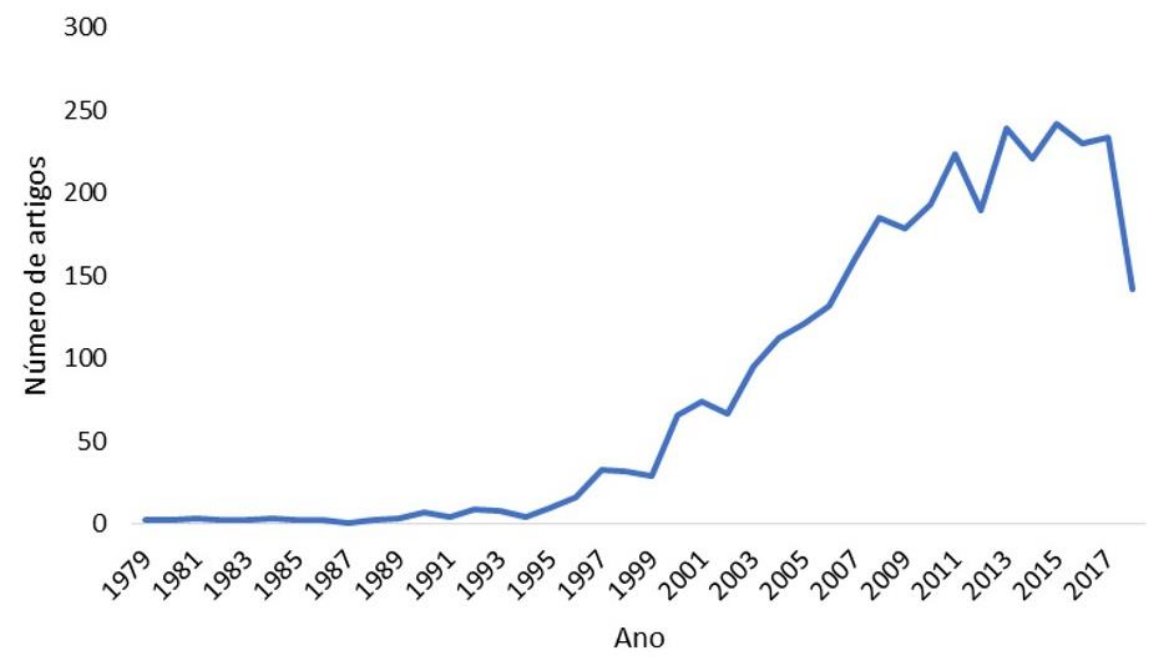

Legenda: Ano-Número de publicações
$1979-2 ; 1980-2 ; 1981-3 ; 1982-2 ; 1983-2 ; 1984-3 ; 1985-2 ; 1986-2 ; 1987-1 ; 1988-2 ; 1989-3 ; 1990-7 ; 1991-4 ; 1992-9 ; 1993-8 ; 1994-4 ; 1995-10 ; 1996-16 ; 1997$ 33; 1998-32; 1999-29; 2000-66; 2001-74; 2002-67; 2003-95; 2004-113; 2005-121; 2006-132; 2007-160; 2008-185; 2009-179; 2010-193; 2011-224; 2012-190 2013-239; 2014-221; 2015-242; 2016-230; 2017-234; 2018-142.

Figura 1: Quantidade de publicações por ano com a expressão de busca 'intangible' and 'assets'.

No tocante às oscilações no volume de publicações, observa-se que elas foram mais frequentes a partir de 1997. Comparando por décadas as oscilações percebidas na série, nota-se que durante a década de 1980 essas variações foram mais discretas, visto que o volume de publicações nessa época foi baixo e praticamente igual em todos os anos. Nas décadas de 1990, período em que se inicia o processo de crescimento da quantidade de publicações, e 2000, é possível perceber que as oscilações aparecem com mais frequência e maior intensidade. Contudo, é a partir da década de 2010 que esse fenômeno fica mais evidente. Nesse período, percebe-se uma tendência de que o volume de publicações oscila de ano para ano, registrando os maiores resultados em 2013 (239) e 2015 (242) e os menores em 2012 (190) e 2018 (142).

O aumento do número de publicações ao longo da série temporal considerada pode ser um reflexo do crescimento da produção acadêmica em escala mundial e da ampliação da cobertura da quantidade de revistas indexadas. Além disso, os periódicos precisam atender aos requisitos de regularidade de publicações e de agilidade no fornecimento de informações para que continuem indexados nas bases bibliográficas [20].

Extrapolando a análise bibliométrica e considerando as mudanças ocorridas no contexto econômico global, compreende-se que o crescimento observado no número de publicações pode estar associado à transição da economia industrial para a economia do conhecimento. De acordo com [21], contexto em que a informação, o conhecimento, a ciência, a tecnologia e a inovação, elementos intrínsecos ao processo de geração de ativos intangíveis, ganharam importância central, tanto no ambiente acadêmico quanto de negócios.

Os novos paradigmas impostos pela economia baseada no conhecimento exigem, progressivamente, capacidade de investimentos em Pesquisa e Desenvolvimento (P\&D) como pressuposto básico para a melhoria do desenvolvimento econômico, tecnológico e competitivo de países, instituições e industrias. As nações que se desenvolveram ao longo do tempo investiram primorosamente no capital intelectual e na geração de tecnologia, a exemplo da Finlândia, Coreia do Sul e Estados Unidos que, mesmo em momentos de crises, priorizaram as políticas de Ciência, Tecnologia e Inovação (CT\&I). De fato, os países que mais investem em P\&D e na geração de ativos intangíveis são os que ocupam posição de destaque no cenário mundial [22, 23].

A produção científica sobre ativos intangíveis vem sendo originada em diversas regiões do mundo. Do volume de artigos publicados na base SCOPUS no período pesquisado (3.283), 3.065 são resultados de pesquisas oriundas de 98 países, e 218 (6,6\%) não tiveram sua origem geográfica identificada. Analisando o montante de publicação dos 98 países identificados (3.065), percebeuse que $84,2 \%$ (2.580) desse total são provenientes de apenas 15 territórios (Figura 2). 


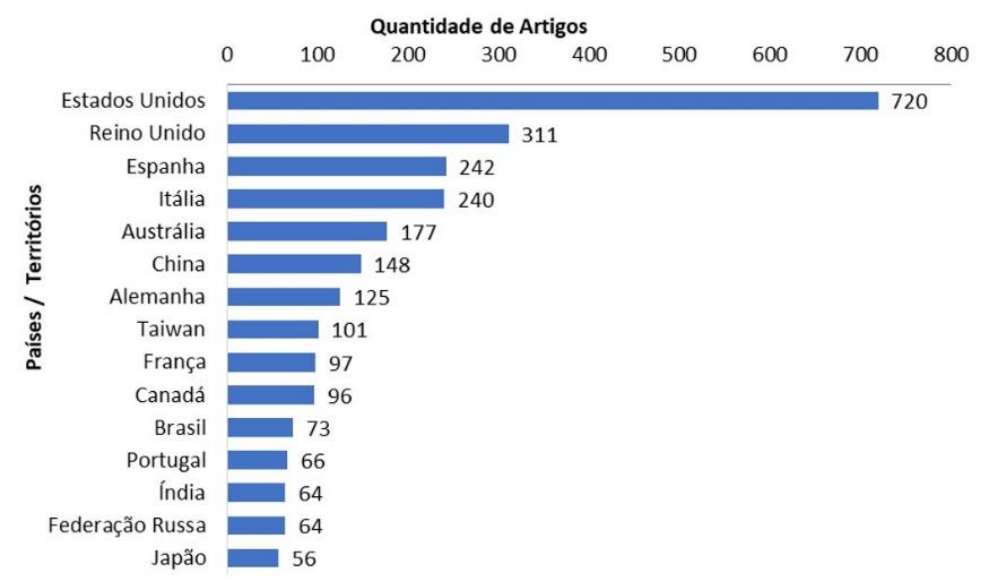

Figura 2: Ranking dos 15 países/territórios de origem das publicações com a expressão de busca 'intangible' and 'assets'.

Observa-se a participação de dois diferentes tipos de economias na classificação dos países e/ou territórios de origem das publicações sobre o tema: o grupo dos países desenvolvidos; e o grupo dos países considerados emergentes, notadamente, todos pertencentes ao BRICS. Do total de artigos publicados pelos 15 países e/ou territórios, 82,6\% são oriundos do grupo dos países desenvolvidos e 17,4\% dos países emergentes (Figura 2). Corroborando as explicações de Tigre (2014) [24], a participação mais ativa do grupo dos países desenvolvidos já era esperada, uma vez que, tradicionalmente, as economias desenvolvidas investem em $\mathrm{P} \& \mathrm{D}$, na expansão do conhecimento e da base científica.

A participação dos países emergentes, especialmente dos BRICS, na produção e difusão do conhecimento sobre ativos intangíveis evidencia a importância das pesquisas básicas e aplicadas nesses territórios. Significa que estes países de economias periféricas, mas com elevado potencial de crescimento econômico, estão investindo na geração de capital intelectual e estrutural para atingir o desenvolvimento econômico atrelado ao desenvolvimento humano e social $[25,26]$.

De acordo com a classificação disponibilizada na própria base bibliográfica, a produção científica sobre ativos intangíveis identificada no recorte temporal adotado, está disposta em 26 subáreas do conhecimento. Nota-se um baixo volume de publicações sobre o tema na área de Educação. As pesquisas abordando o tema no contexto das IES aparecem na classificação da subárea Multidisciplinar, que somadas às pesquisas das subáreas Ciências da Terra e Planetárias, Ciências Agrárias e Biológicas, Ciência de materiais, Energia, Bioquímica, Genética e Biologia Molecular, Psicologia, Engenharia química, Imunologia e Microbiologia, Farmacologia, Toxicologia e Farmacêutica, contabilizam apenas 6,4\% da produção identificada. As subáreas de Negócios, Gestão e Contabilidade, Economia, Econometria e Finanças e Ciências Sociais são as que apresentam os maiores volumes de produção, respectivamente $34,1 \%, 15,9 \%, 15,5 \%$.

Quando a pesquisa se limitou a identificar as publicações sobre ativos intangíveis enquanto elementos diferenciadores e geradores de valor organizacional, empregou-se a expressão de busca 'intangible' and 'assets' and 'value creation'. Foram identificados 51 artigos, publicados no período de 2016 a 2018. Contudo, aplicando o critério de inclusão, apenas artigos em periódicos revisados por pares, e desconsiderando as repetições, foram selecionados e analisados 31 artigos.

Seguindo o roteiro de análise dos artigos e observando as taxonomias dos ativos intangíveis propostas por Kayo at al. (2006) [12] - Ativos humanos, Ativos de inovação, Ativos estruturais e Ativos de relacionamento - e Macagnan (2007) [13] - Indicadores de capital humano, Capital estrutural tecnológico, Capital estrutural organizativo, Capital relacional do negócio e Capital relacional social- buscou-se extrair a intencionalidade dos objetivos de cada artigo, no tocante aos grupos de ativos intangíveis abordados como elementos geradores de valor organizacional.

Quando analisados os objetivos, foi possível perceber que 77,4\% dos artigos apresentaram a intenção de verificar o papel de mais de um grupo de ativos intangíveis nos processos de criação de valor. Percebeu-se que 12,9\% abordaram a importância da divulgação das informações 
relativas aos ativos intangíveis em relatórios e demonstrativos. Por outro lado, 9,7\% dos artigos objetivaram destacar a importância da identificação dos ativos intangíveis e da avaliação do seu impacto na criação de valor organizacional.

De maneira geral, nota-se que todos os grupos de ativos intangíveis foram considerados pelas pesquisas como elementos geradores de valor organizacional. Desconsiderando os ativos humanos ou indicadores de capital humano, em uma primeira análise, observa-se que ao capital intelectual (formado pelos grupos de ativos intangíveis) é conferida uma responsabilidade significativa em relação à criação de valor. De um total de 45 intenções, implícitas ou explicitas nos objetivos, esse grupo se destacou com 22,2\% (Figura 3). Logo, a abordagem conferida nesses objetivos evidencia que a geração de valor não é resultante especificamente de um grupo de ativos intangíveis, mas da interação entre eles. Piontkewicz e Freitas (2018) [27], destacam que a fragmentação do capital intelectual em grupos tem a finalidade de facilitar a identificação, entendimento e gestão dos ativos intangíveis, no entanto é a interação e intercâmbio entre as dimensões que promovem a geração e a sustentabilidade de valor organizacional.

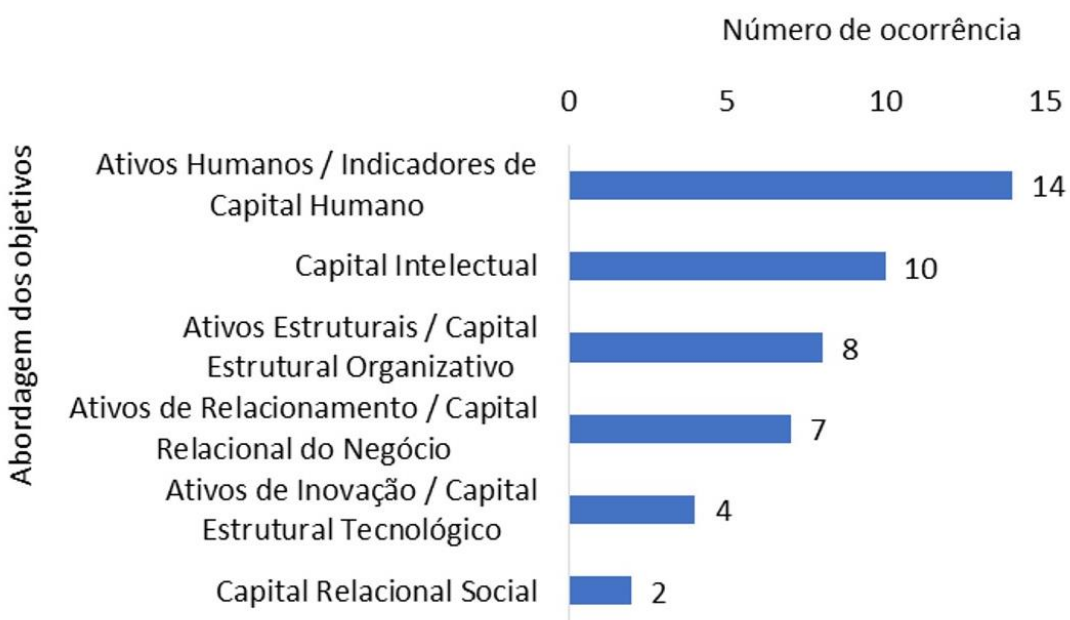

Figura 3 - Identificação da intencionalidade dos objetivos dos artigos.

Analisando por grupos de ativos intangíveis, observa-se que os ativos humanos ou indicadores de capital humano, ativos estruturais ou capital estrutural organizativo e ativos de relacionamento ou capital relacional do negócio foram abordados com mais frequência nos objetivos, 31,1\%, $17,8 \%$ e 15,6\%, respectivamente. Herremans et al. (2011) [28], recomendam que esses três grupos sejam considerados, gerenciados e monitorados numa perspectiva integrativa para que possam conferir às organizações as capacidades necessárias para se ajustarem ao ambiente externo. Para Battagello et al. (2016) [29], os ativos intangíveis quando alinhados às estratégias organizacionais, combinados e internalizados para um nível corporativo são essenciais para a criação e entrega de valor no longo prazo.

A relação positiva entre a interação dos grupos de ativos intangíveis e a criação de valor organizacional é almejada. Contudo, Mirzaee e Ghaffari (2018) [30], enfatizam que os ativos humanos ou indicadores de capital humano, ativos baseados no conhecimento, são os recursos estratégicos fundamentais para a geração de outros ativos intangíveis. Dessa forma, se comparados aos ativos estruturais ou capital estrutural organizativo, apresentam maior influência na geração de vantagens competitivas e maior desempenho financeiro [31].

Dentre os grupos de ativos intangíveis, nota-se que os ativos de inovação ou capital estrutural tecnológico $(8,9 \%)$ e os de capital relacional social $(4,4 \%)$ foram abordados com menor frequência nos objetivos dos artigos selecionados. Assim como os demais, esses dois grupos são apontados como elementos estratégicos na geração de valor organizacional. A inovação, por exemplo, gera vantagem competitiva sustentável que potencializa a criação de valor e contribui para a sustentação e viabilização econômica das organizações [32]. 
A importância dos ativos de relacionamento ou capital relacional do negócio e do capital relacional social ficou evidente nos artigos que apresentaram a intencionalidade de expor a relevância da divulgação de informações relativas aos ativos intangíveis, bem como de destacar a necessidade do reconhecimento e da avaliação do seu impacto no desempenho das empresas. A combinação de informações quantitativas e qualitativas em relação aos processos-chave e desempenho da organização fortalece a relação com os diversos stakeholders. De acordo com Boyko e Derun (2016) [33], isso possibilita uma compreensão mais ampla das interrelações entre os elementos que compõem a estrutura da organização e que influenciam nas operações comerciais e no alcance dos objetivos de curto, médio e longo prazos. Ademais, Romero (2016) [34] e Albertini (2019) [35], sinalizam que a divulgação de informações relacionadas ao capital social e relacional, aos princípios, à filosofia e à cultura corporativa contribuem para melhorar o nível de transparência e reputação das organizações junto aos públicos estratégicos.

A avaliação dos impactos dos grupos de ativos intangíveis no desempenho financeiro das organizações e na capacidade de criação de valor é um processo necessário. Isso permite que sejam identificados os grupos de ativos que exercem maior influência na competitividade do setor. Para as empresas que operam no setor de serviços financeiros, mineração e energia, por exemplo, a eficiência do capital humano tem uma forte associação positiva com a rentabilidade, enquanto a eficiência do capital estrutural impacta em menor intensidade. Já no setor de tecnologia da informação, o capital estrutural é considerado um recurso estratégico, pois promove uma série de vantagens na execução dos processos operacionais e na criação de valor para a empresa [36-38].

Em relação aos tipos de organizações pesquisadas, observa-se que o setor empresarial/industrial foi o mais investigado. Do total de artigos selecionados (31), 64,5\% desenvolveram as pesquisas no âmbito de empresas/indústrias com fins lucrativos, 9,7\% em instituições financeiras, 3,2\% em incubadoras de empresas de base tecnológica. Contudo, em 22, $6 \%$ dos artigos não foi possível identificar, nem nos resumos, nem nas conclusões o tipo de organização pesquisada (Figura 4).

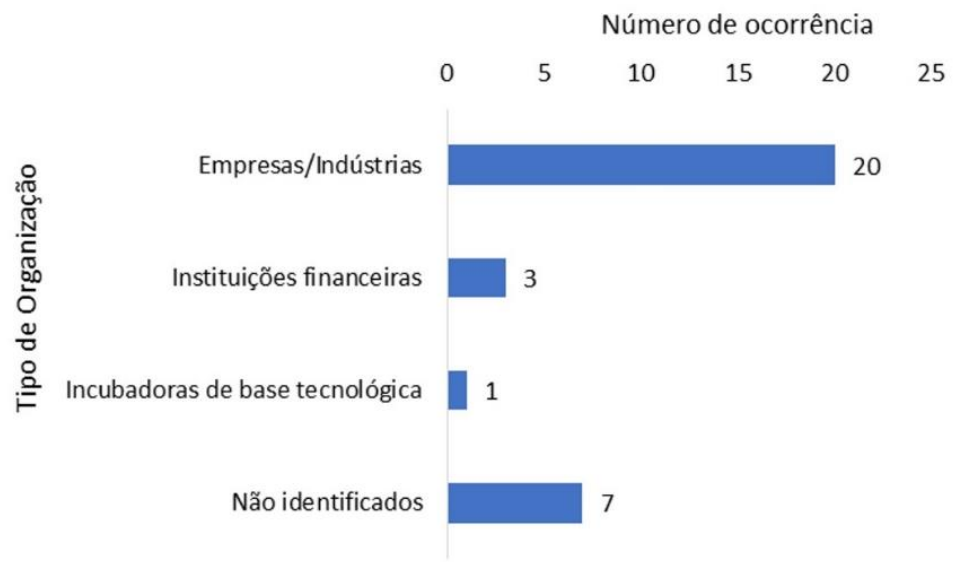

Figura 4: Número de ocorrência por tipos de Organizações pesquisadas identificadas a partir dos resumos ou conclusões dos artigos selecionados.

Considerando o recorte temporal, bem como a base bibliográfica pesquisada, observa-se um direcionamento dos estudos para o segundo setor da economia. São pesquisas focadas em demonstrar que os investimentos em ativos intangíveis são determinantes para a criação de valor no longo prazo e geração de vantagens competitivas sustentáveis. Dentre as empresas/indústrias pesquisadas, destacam-se as do setor logístico, do setor de tecnologias de informação e comunicação (TIC), do setor elétrico, do setor farmacêutico e do setor hoteleiro.

$\mathrm{O}$ valor dos negócios é, em grande medida, determinado pelo valor dos ativos intangíveis. Em uma economia baseada no conhecimento, esses ativos representam os principais geradores de valor organizacional. Ao contrário dos ativos tangíveis, cujo valor vai se deteriorando com o uso, os ativos intangíveis, sobretudo os humanos e relacionais, tendem a elevar o seu valor com o 
passar do tempo. O entendimento da significância dos ativos intangíveis influencia, sobremaneira, na definição das estratégias de criação e entrega de valor [39, 40].

Buscando identificar o volume de publicação no âmbito do setor educacional, especificamente das IES, empregou-se duas expressões de buscas intangible and assets and value creation and university' $\mathrm{e}$ 'intangible and assets and value creation and higher education institutions'. Com o recorte temporal definido inicialmente, 2016 a 2018, localizou-se apenas 1 artigo publicado em 2017. Empregando as duas expressões de busca e um recorte temporal mais amplo, 2014 a 2018 , retornaram três artigos. Esses resultados corroboram o baixo percentual de publicações sobre ativos intangíveis na área de educação, sinalizados anteriormente nesta pesquisa. Assim, é possível observar que, apesar de se configurarem como lócus de produção intelectual, a temática ainda é pouco abordada no contexto de valorização da capacidade produtiva da IES.

Comparando o volume de produção na área de educação com outras áreas identificadas nesta pesquisa, percebe-se que as IES atuam apenas como fomentadoras das linhas de pesquisas, sendo que o valor gerado pelo desenvolvimento de pesquisas básicas ou aplicadas é incorporado, na maioria das vezes, aos pesquisadores, através das métricas de avaliação curricular, ou ao mercado, a partir da transferência de tecnologia.

O volume de pesquisas abordando a produção intelectual das IES e evidenciando o impacto dessa produção no valor da instituição se apresentou de maneira incipiente. Seria fundamental que a gestão acadêmica compreendesse as interrelações entre o capital intelectual, os princípios norteadores e os objetivos estratégicos para que consiga converter suas ações em valor, tanto para a instituição quanto para a sociedade. Ainda que as ações das IES devam estar voltadas para o atendimento às demandas da sociedade, nota-se que elas estão investindo recursos em pesquisas e produzindo ativos intangíveis que serão absorvidos, quase que exclusivamente, por outros setores da economia, visto que muitos desses resultados não são revertidos em ganhos de valor para a instituição.

Seguindo os mesmos procedimentos de análise dos artigos, percebeu-se que os objetivos foram direcionados para identificar o papel dos grupos de ativos humanos ou indicadores de capital humano, ativos de inovação ou capital estrutural tecnológico e do capital intelectual (todos os grupos de ativos intangíveis) na criação de valor no contexto das IES. Brătianu e Pînzaru (2015) [41] relatam que o capital intelectual de uma IES precisa ser compreendido em uma visão holística, a partir da integração entre competências, capacidades e habilidades essenciais, bem como pela governança da instituição. São recursos singulares que devem estar alinhados com o pensamento e objetivos estratégicos da instituição. Portanto, cabe aos gestores identificar os benefícios futuros do capital intelectual para a obtenção de vantagens competitivas em um contexto global.

A criação de valor e a obtenção de vantagens competitivas, desde a transição da economia industrial para a economia baseada no conhecimento, esteve atrelada à capacidade de geração e transformação de ativos intangíveis em elementos diferenciadores, inclusive no setor educacional. A identificação e compreensão das interrelações entre os ativos intangíveis e os vários elementos das IES, como a filosofia, objetivos estratégicos e processos gerenciais, são fundamentais para auxiliar os gestores nos processos de tomada de decisão e na elaboração de estratégias capazes de converter seu capital intelectual em valor organizacional [42].

É necessário implementar modelos de gestão acadêmica capazes de transformar os resultados advindos das ações dos pesquisadores em valor organizacional. A divulgação de informações referentes aos resultados provenientes principalmente do ensino e da pesquisa, por exemplo, seja a partir de relatórios de capital intelectual ou por meio de pesquisas desenvolvidas internamente, representa uma maneira de monitorar os ganhos obtidos com a geração de ativos intangíveis.

Os ativos intangíveis, sobretudo os grupos dos ativos humanos ou indicadores de capital humano e os ativos de inovação ou capital estrutural tecnológico, são gerados a partir de processos intraorganizacional e interorganizacional. Para Abduljawad (2015) [43], as cooperações entre universidades, indústrias e governo são fundamentais para impulsionar a capacidade de geração de ativos intangíveis e o consequente desenvolvimento econômico, social e tecnológico nos níveis organizacional e nacional.

As IES apresentam potencial para desenvolverem pesquisas que contribuam para o avanço no campo científico ou tecnológico [44]. Esse potencial é favorecido pela disponibilidade de recursos 
humanos qualificados e capacidade estrutural da instituição. Nesse sentido, torna-se necessário o estabelecimento de estratégias para que os resultados dos processos institucionais sejam convertidos em valor organizacional. O reconhecimento e gerenciamento dos ativos intangíveis, resultantes do ensino, pesquisa e extensão, contribuem para elevar os investimentos em educação, formação e pesquisas nas IES.

As IES, por meio de seus pesquisadores, contribuem eminentemente para o progresso das diversas áreas do conhecimento. Os investimentos em ativos estruturais ou capital estrutural organizativo são fundamentais para a criação e entrega de valor, visto que a infraestrutura apoia a prática profissional e permite o funcionamento da organização [45, 46]. Secundo et al. (2017) [47] enfatizam que os investimentos em ativos estruturais provocam melhorias na execução dos processos internos e no atendimento às demandas do ambiente externo.

O capital intelectual das IES, formado sobretudo pelo capital humano, relacional e estrutural, provém de uma série de investimentos a longo prazo, por isso torna-se necessário converte-lo em ganhos para a instituição. A trajetória de causa-efeito da criação de valor a partir do capital intelectual é complexa e demanda atenção especial para os processos de geração, identificação, mensuração e gestão desses ativos. O valor da marca da IES, por exemplo, é resultante dos investimentos em ativos de relacionamento, o que influencia diretamente na percepção dos stakeholders. A valorização do capital humano, recurso estratégico para a criação de valor nas IES, é primordial para evitar a evasão de cérebros da instituição, bem como promover maior alinhamento entre as práticas docentes e projetos institucionais [48].

Nas pesquisas sobre ativos intangíveis o setor público ainda é pouco abordado. As IES, consideradas atores críticos nos processos de criação, difusão e transferência do conhecimento, precisam adotar modelos de gestão acadêmica capazes de transformar seu potencial de geração de ativos intangíveis em valor para os públicos estratégicos da instituição e para a sociedade. $\mathrm{O}$ uso de ferramentas de gestão do capital intelectual que permitam a implementação de abordagens de identificação, mensuração e gerenciamento desse capital como parte integrante da gestão estratégica da IES, fornece uma estrutura efetiva para elevar a competitividade da instituição e a capacidade de criação e entrega de valor $[41,49]$.

\section{CONCLUSÃO}

$\mathrm{Na}$ literatura são apresentadas diversas taxonomias para os ativos intangíveis ou capital intelectual. Seria relevante que as classificações estivessem alinhadas com as especificidades das organizações, uma vez que isso facilitaria a identificação dos diversos componentes dos grupos de ativos intangíveis. No contexto das IES, por exemplo, é necessário que a classificação dos ativos intangíveis reconheça os resultados dos processos de ensino, pesquisa e extensão.

Os resultados evidenciaram que todos os grupos de ativos intangíveis são fundamentais na criação de valor organizacional, e que as pesquisas na área vêm ganhando repercussão no ambiente científico ao longo do tempo. Além disso, observou-se a existência de um núcleo de países/territórios mais produtivo, em relação à origem dessas publicações. Também foi possível observar que há uma maior quantidade de publicações na subárea do conhecimento Negócios, Gestão e Contabilidade, fato que pode explicar a maior concentração de pesquisas no âmbito das empresas/indústrias.

Ademais, notou-se um reduzido volume de pesquisas com o objetivo de identificar o papel dos ativos intangíveis na criação de valor no contexto das IES. Os ativos intangíveis, como o capital humano, representam os elementos estratégicos de criação de valor no setor educacional. $\mathrm{O}$ progresso das diversas áreas do conhecimento se sustenta nos processos de ensino, pesquisa e extensão desenvolvidos a partir do capital humano e estrutural das IES. Assim, esperava-se um maior número de pesquisas sobre o tema, tanto abordando a produção intelectual, quanto demonstrando o seu impacto na criação de valor organizacional.

As IES apresentam uma ambiência propícia para o desenvolvimento de pesquisas sobre ativos intangíveis. A produção intelectual da IES, quando percebida como objeto de pesquisa, pode gerar informações ou indicadores para apoiar a gestão acadêmica e ampliar a transparência da instituição. Pesquisas demonstrando a atuação dessas instituições no desenvolvimento científico 
e tecnológico podem contribuir para a criação de valor superior. A difusão do conhecimento, a criação de produtos ou oferta de serviços, resultantes das suas atividades, além de fortalecer o valor da marca diante dos públicos estratégicos, apoia a tomada de decisão em relação aos investimentos em ciência, tecnologia e inovação.

A principal limitação desta pesquisa se refere às expressões de busca em relação aos ativos intangíveis e criação de valor nas IES. Recomenda-se para estudos futuros que a busca seja realizada substituindo a expressão 'ativos intangíveis' pelos grupos de ativos: capital intelectual, capital humano, capital estrutural, capital relacional, isso poderá ampliar o número de publicações na área de educação.

\section{REFERÊNCIAS BIBLIOGRÁFICAS}

1. Perez MM, Famá R. Ativos intangíveis e o desempenho empresarial. Rev Contab Finanç. 2006 Jan;17(40):7-24. doi: 10.1590/S1519-70772006000100002

2. Da Silva A, De Souza TR, Klann RCA. Influência dos ativos intangíveis na relevância da informação contábil. Rev Contemp Contab. 2017 Jan;14(31):26-45. doi: 10.5007/2175-8069.2017v14n31p26

3. Magro CBD, Da Silva A, Padilha D, Jlann RC. A relevância dos ativos intangíveis em empresas de alta e baixa tecnologia. Nova Econ. 2017 Set;27(3):609-40. doi: 10.1590/0103-6351/3214

4. Tsai CF, Lu YH, Yen DC. Determinants of intangible assets value: The data mining approach. KnowlBased Syst. 2012 Jul;31:67-77. doi: 10.1016/j.knosys.2012.02.007

5. Lev B, Gu F. The end of accounting and the path forward for investors and managers. John Wiley \& Sons; 2016.

6. Perez MM, Famá R. Características estratégicas dos ativos intangíveis e o desempenho econômico da empresa. Unisanta. 2015 Nov;4(2):107-123.

7. Carneiro JD. Pronunciamentos técnicos contábeis 2012. Brasília (DF): Comitê de Pronunciamentos Contábeis; 2013.

8. Cavalcanti JMM, Amaral HF, Correia LF, Louzada LC. Proposta de convergência teórica das perspectivas das finanças e da contabilidade na avaliação de ativos intangíveis. Rev Universo Contábil. 2017 Out;13(4):177-93. doi: 10.4270/ruc.2017431

9. Edvinsson L, Malone MS. Capital intelectual. São Paulo (SP): Makron; 1998.

10. Stewart TA. Capital intelectual: a nova vantagem competitiva das empresas. 7. ed. São Paulo (SP): Campus; 1998.

11. Jóia LA. Medindo o capital intelectual. Rev Adm Empres. 2001 Abr;41(2):54-63. doi: 10.1590/S003475902001000200006

12. Kayo EK, Kimura H, Martin DML, Nakamura WT. Ativos intangíveis, ciclo de vida e criação de valor. Rev Adm Contemp. 2006 Jul/Set;10(3):73-90. doi: 10.1590/S1415-65552006000300005

13. Macagnan CB. Condicionantes e implicación de revelar activos intangibles. Barcelona (CT): Universitat Autònoma de Barcelona; 2007.

14. Barros ASX. Expansão da educação superior no brasil: limites e possibilidades. Educ Soc. 2015 Abr;36(131):361-90. doi: 10.1590/ES0101-7330201596208

15. Carvalho CHA. A mercantilização da educação superior brasileira e as estratégias de mercado das instituições lucrativas. Rev Bras Educ. 2013 Jul;18(54):761-801. doi: 10.1590/S141324782013000300013

16. Mancebo D, Do Vale AA, Martins TB. Políticas de expansão da educação superior no Brasil 1995 2010. Rev Bras Educ. 2015 Jun;20(60):31-50. doi: 10.1590/S1413-24782015206003

17. De Paula ASN. Educação a distância e a expansão mercantil do ensino superior brasileiro. Trabalho Necessário. 2016 Jan;14(23):94-117. doi: 10.22409/tn.14i23.p9603

18. Córcoles YR. The inadequate information model of Spanish universities: the relevance of intelectual capital disclosure. J Inf Know Manag. 2013 Nov;12(3):14-26. doi: 10.1142/S0219649213500226

19. Sangiorgi D, Siboni B. The disclosure of intellectual capital in Italian universities: What has been done and what should be done. J Intellect Cap. 2017 Apr;18(2):354-72. doi: 10.1108/JIC-09-2016-0088

20. Mugnaini R, Jannuzzi P, Quoniam L. Indicadores bibliométricos da produção científica brasileira: uma análise a partir da base Pascal. Ciênc Inf. 2004 Mai;33(2):123-31. doi: 10.1590/S010019652004000200013

21. Theis IMA. Sociedade do Conhecimento realmente existente na perspectiva do desenvolvimento desigual. Rev Bras Gest Urbana. 2013 Jan;5(1):133-48. doi: 10.7213/urbe.7790

22. Arbix G, Miranda Z. Inovação em tempos difíceis. Plural. 2015 Jan;22(2):18-36. doi: 10.11606/issn.2176-8099.pcso.2015.112428 
23. Sperancini JHBS, Cappa J, Machado LC. A necessidade de avaliação da política de fomento à inovação tecnológica no Brasil. Multitemas. 2018 Jan;23(53):103-28. doi: 10.20435/multi.v23i53.1323

24. Tigre PB. Gestão da inovação: a economia da tecnologia no Brasil. Rio de Janeiro (RJ): Elsevier; 2014.

25. Aguiar P. Agências de notícias, estado e desenvolvimento: modelos adotados nos países BRICS. Braz Journal Res. 2016 Abr;12(1):34-59. doi: 10.25200/BJR.v12n1.2016.831

26. Lobato LVC. A questão social no projeto do BRICS. Ciênc Saúde Colet. 2018 Jul;23(7):2133-46. doi: $10.1590 / 1413-81232018237.09072018$

27. Piontkewicz R, Freitas MCD. Pré-requisitos necessários para um sistema de informação contábil realizar a gestão do capital intelectual. Rev Tecnol Soc. 2018 Jan;14(31):171-88. doi: $10.3895 /$ rts.v14n31.7023

28. Herremans IM, Isaac RG, Kline TJB, Nazari JA. Intellectual Capital and Uncertainty of Knowledge: Control by Design of the Management System. J Bus Ethics. 2011 Aug;98:627-40. doi: 10.1007/s10551-010-0642-7

29. Battagello FB, Cricelli L, Grimaldi M. Benchmarking strategic resources and business performance via an open framework. Int J Product Perform Manag. 2016 Mar;65(3):324-50. doi: 10.1108/IJPPM-082014-0129

30. Mirzaee S, Ghaffari A. Investigating the impact of information systems on knowledge sharing. J Knowl Manag. 2018 Apr;22(3):501-20. doi: 10.1108/JKM-08-2017-0371

31. Nawaz T, Haniffa R. Determinants of financial performance of Islamic banks: an intellectual capital perspective. J Islam Account Bus Res. 2017 Dec;8(2):130-42. doi: 10.1108/JIABR-06-2016-0071

32. Teh CC, Kayo EK, Kimura H. Marcas, patentes e criação de valor. RAM: Rev Adm Mackenzie. 2008 Jan;9(1):86-106. doi: 10.1590/S1678-69712008000100005

33. Boyko K, Derun I. Disclosure of non-financial information in corporate social reporting as a strategy for improving management effectiveness. J Int Stud. 2016 Nov;9(3):159-77. doi: 10.14254/2071$8330.2016 / 9-3 / 13$

34. Romero FT. Información de los recursos intangibles ocultos: memorias de sostenibilidad o informe anual. Eur Res Manag Bus Econ. 2016 May;22(2):101-9. doi: 10.1016/j.iedee.2015.06.001

35. Albertini E. Integrated reporting: an exploratory study of French companies. J Manag Gov. 2019 Jun;23(1):513-35. doi: 10.1007/s10997-018-9428-6

36. Tello EA, Velasco JMAP. Inteligencia de negocios: estrategia para el desarrollode competitividad en empresas de base tecnológica, en Tijuana, B.C. Contad Adm. 2016 Jan;61(1): 127-58. doi: 10.1016/j.cya.2015.09.006

37. Lombardi R, Del Giudice M, Caputo A, Evangelista F, Russo G. Governance and assessment insights in information technology: The Val it model. J Knowl Econ. 2016 Mar;7(4):292-308. doi: 10.1007/s13132-015-0328-6

38. Tandon K, Purohit H, Tandon D. Measuring intellectual capital and its impact on financial performance: empirical evidence from CNX Nifty Companies. Glob Bus Rev. 2016 Jun;17(4):980-99. doi: $10.1177 / 0972150916645703$

39. Dženopoljac V, Janoševic S, Bontis N. Intellectual capital and financial performance in the Serbian ICT industry. J Intellect. Cap. 2018 Apr;17(2):373-96. doi: 10.1108/JIC-07-2015-0068

40. Boronos V, Plikus I, Aleksandrov V. Financial and accounting approaches to definition of the intangible factors impact on the value of the company. Econ Ann. 2016 Jul;160(7-8):121-5.

41. Brătianu C, Pînzaru F. Challenges for the university intellectual capital in the knowledge economy. Manag Dyn Knowl Economy. 2015 Dec;3(4):609-27.

42. Boj JJ, Rodriguez-Rodriguez R, Alfaro-Saiz JJ. An ANP-multi criteria based methodology to link intangible assets and organizational performance in a Balanced Scorecard context. Decis Support Syst. 2014 Dec;68:98-110. doi: 10.1016/j.dss.2014.10.002

43. Abduljawad H. Challenges in Cultivating knowledge in university-industry-government partnerships Qatar as a case study. The Muslim World. 2015 Dec;105:58-77. doi: 10.1111/muwo.12080

44. Freitas Jr OG, Carvalho VDH, Barros PAM, Braga MM. Uma arquitetura para sistemas de gestão do conhecimento orientada a grupos de pesquisas e desenvolvimento. Perspect Gest Conhecimento. 2017 Mar;7(3):126-44.

45. Cordeiro ALAO, Fernandes JD, Maurício MDALL, Silva RMO, Barros CSMA, Romano CMC. Capital estrutural na gestão das enfermeiras em hospitais. Texto Contexto Enfer. 2018 Jun;27(2):1-10. doi: 10.1590/0104-07072018004880016

46. Somayyeh M, Ali G. Investigating the impact of information systems on knowledge sharing. J Knowl Manag. 2018 Feb;22(3):501-20. doi: 10.1108/JKM-08-2017-0371

47. Secundo G, Del Vecchio P, Dumay J, Passiante G. Intellectual capital in the age of Big Data: establishing a research agenda. J Intellect Cap. 2017 Apr;18(2):242-61. doi: 10.1108/JC-10-20160097. 
48. Ferreira LS, Vasconcelos MCRL, Pereira FCM. Mensuração do capital intelectual docente: avaliação e reconhecimento por meritocracia em uma instituição de ensino superior. Perspect Ciênc Inf. 2019 Oct./Dec;24(4):112-31. doi: 10.1590/1981-5344/3866

49. Secundo G, Elena-Perez S, Martinaitis Z, Leitner KH. An intellectual capital maturity model (ICMM) to improve strategic management in European universities: A dynamic approach. J Intellect Cap. 2015 Apr;16(2):419-42. doi: 10.1108/JIC-06-2014-0072 